\title{
Clinical signs in diffuse cerebral dysfunction
}

\author{
L.R. J E N K Y N, D. B . W A L S H C . M . C U L V E R, \\ A N D A. G. RE E V E S
}

From the David Prosser Neurology Research Laboratories, Division of Neurology, Department of Medicine, and the Department of Psychiatry, Dartmouth-Hitchcock Medical Center, Hanover, New Hampshire, USA

S UMMARY Abnormal responses to 13 questions from a typical mental status examination and 32 signs of neurological dysfunction were correlated with increasing degrees of cognitive impairment as measured by the Halstead-Reitan Neuropsychological Battery. Thirteen of these factors were found to be useful predictors of diffuse cerebral dysfunction when combined into a brief screening examination for application at the bedside.

The diagnosis of the presence or absence of diffuse cerebral dysfunction-that is, delirium (reversible) or dementia (irreversible)-is a frequent problem, most often encountered with elderly patients but by no means limited to them (Katzman, 1976). When the patient's cognitive integrity is in question, it is important to document the impairment accurately, rapidly, and economically in order to institute therapy for reversible disease processes (Marsden and Harrison, 1972). One tool for the immediate and objective measurement of cerebral function has been examination of the mental status at the bedside. Orientation, memory, problem-solving, and abstraction may be evaluated in a few minutes with a short collection of well chosen questions. These means of appraisal are popular and frequently valuable, but have certain prominent weaknesses. The tests and their administration and interpretation are difficult to standardise. Given a consistent examination of mental status, distinction between low intellect and genuine cortical impairment is subjective and is based on extensive experience with patients of all ages, capabilities, and levels of education. In addition, bedside examinations of mental status have not been correlated systematically with more fully documented measures of neuropsychological function.

Extensive psychometric testing represented by

This study was supported in part by the Hitchcock Foundation and Public Health Service Grant MH25621.

Address for reprint requests: Dr L. R. Jenkyn, Division of Neurology, Department of Medicine, Dartmouth-Hitchcock Medical Center, Hanover, New Hampshire 03755, USA.

Accepted 24 May 1977
Reitan's modification of the Halstead Battery (Reitan and Davison, 1974) provides a more precise estimate of cognitive function. This type of highly standardised testing evaluates many intellectual, problem-solving, and perceptual-motor abilities over a two to three hour testing period. The examination in many ways may be regarded as an extension and standardisation of certain parts of both the mental status and neurological examinations, and may help in making a more objective assessment. In many clinical situations the Halstead-Reitan Battery has proved very helpful. Its length and cost, however, preclude its use as a routine screening examination.

Clinicians tend to associate certain physical signs with diffuse cerebral dysfunction including the grasp, palmomental, and feeding reflexes. Many of these signs are present in infancy but become inhibited and unelicitable with increasing age and cortical maturity. Their reappearance later in life in the absence of focal lesions is felt to be secondary to release (disinhibition) from cortical suppression (Ingram, 1962; Humphrey, 1964; Paulson and Gottlieb, 1968; Villeneuve et al., 1974). These physical signs are assessed routinely by some clinicians but apparently not at all by others. Their appraisal has the advantage of ease, rapidity, and economy of administration. However, their clinical value has not been standardised nor evaluated systematically (Kahn et al., 1960; Joynt et al., 1962; Hurwitz, 1968; Paulson and Gottlieb, 1968; Isaacs and Akhtar, 1972; Adams and Hurwitz, 1974; Villeneuve et al., 1974; Jenkyn et al., 1975).

The study reported here correlates 13 questions 
from a typical bedside mental status examination and 32 physical signs of neurological dysfunction with degrees of cognitive impairment measured by the Halstead-Reitan Neuropsychological Battery. Thirteen of these 45 factors correlated well with the degree of intellectual impairment and their validity was cross-validated on a second series of cases. Together, they make for a simple examination which may prove useful in screening for cortical dysfunction.

\section{Subjects and methods}

Over a period of 12 months, 90 patients were selected randomly for inclusion in the study from the total patient pool referred to the DartmouthHitchcock Neuropsychology Laboratory. These patients were referred in roughly equal numbers by the psychiatry, neurology, and neurosurgery services. Four patients were eliminated because it was apparent from their history and test results that they were mentally retarded and had no evidence of recently acquired cognitive dysfunction. Ten other patients were eliminated because both their neurological and neuropsychological results indicated that their cortical dysfunction was essentially focal in nature. Seventy-six patients remained whose neuropsychological results indicated either no impairment or some degree of diffuse, bilateral cortical dysfunction. Both inpatients (56) and outpatients (20) were represented. There were 43 males and 33 females with a mean age of 43.8 years (range 16-80). In the majority of cases the reason for referral was to determine whether significant cognitive impairment existed. In a minority of cases the existence of impairment was known or highly suspected and the reason for referral was to gauge its severity.

NEUROPSYCHOLOGICAL TEST BATTERY

All subjects received a standard battery of tests (Reitan and Davison, 1974): The Wechsler Adult Intelligence Scale (WAIS); the Trails Test; the Halstead Battery (Category Test, Tactual Performance Test, Finger Tapping, Rhythm Test, and Speech Sounds Perception Test); the Dynamometer; an Aphasia Screening Test; a SensoryPerceptual Examination; and the Reading part of the Wide Range Achievement Test.

On the basis of their neuropsychological testing results alone, patients were assigned to one of four categories of cognitive functioning: group 1 (no impairment), group 2 (mild impairment), group 3 (moderate impairment), group 4 (marked impairment). The neuropsychologist making this classification (CMC) had no knowledge of the neurological tests described below and, in fact, never saw the patients personally since the neuropsychological testing was carried out by other technicians.

The basis for the fourfold classification was principally certain objective indices described below. These indices were used along with knowledge of the patient's age, education, and occupation to make a final judgment, and specific educational and occupational histories on each subject are available from the authors on request.

One of the objective indices is the Halstead Impairment Index, a decimal value ranging from 0.0 to 1.0 which represents that fraction of the five test measures of the Halstead test battery which lie in the 'impaired' range, (Reitan and Davison, 1974). The mean value, standard deviation, and range on this measure for each of the four groups are shown in Table 1.

Table 1 Mean value, standard deviation, and range on two objective measures for classifying patients

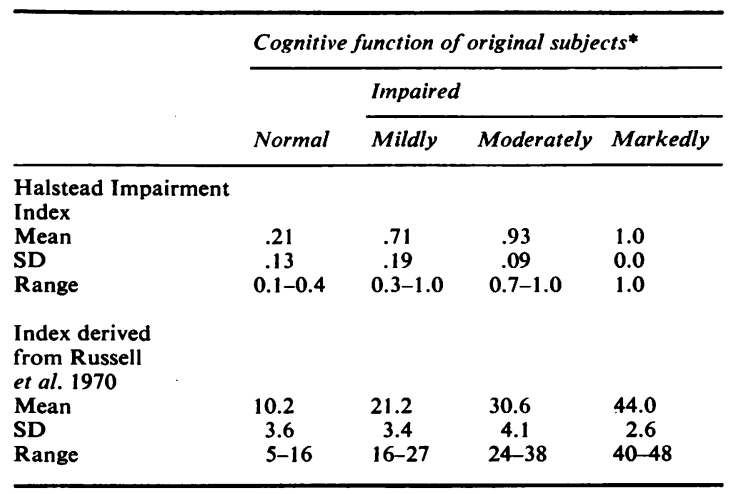

* Determined by neuropsychological evaluation (see Methods).

The other objective index is based on normative scalar values given by Russell et al. (1970). They assign scale values between 0 (best performance) and 5 (worst performance) for various tests used in the battery. These scalar values were computed for 10 test measures in our battery of tests (Category Test; Tactual Performance Test: memory, location, to:al time; Rhythm Test; Speech Sounds Perception Test; Dominant and Non-dominant Finger Tapping; Trails A and B). The mean, standard deviation, and range on this measure for the four groups are also shown in Table 1.

PHYSICAL SIGNS AND MENTAL STATUS ITEMS All patients were tested using the following 45 factors. Where bilateral responses were possible, a 
unilateral abnormal response was considered a sign of diffuse dysfunction because subjects with focal lesions had been excluded from the subject population.

1. Nuchocephalic reflex (Jenkyn et al., 1975) The shoulders of the standing subjects, whose eyes were closed, were turned briskly to the left and/or right, and the position of the head was noted. The reflex was inhibited and normal if the head actively turned in the direction of the shoulder movement after a lag period of approximately half a second. The reflex was present (disinhibited) and abnormal if the head held the original position. Movement of the head and shoulder en bloc, as may be seen with cervical spondylosis, obscured the reflex and prevented assessment of the response.

2. Glabellar blink (Klawans and Goodwin, 1969; Pearce, 1974b) The subject was directed to fix gaze on a point across the room. The examiner's index finger approached the patient from above the forehead outside the visual field. This eliminated visual threat as a stimulus. The glabellar region was then rapidly tapped eight to 10 times. The normal response was for reflex closure of the eyelids to be inhibited after two or three taps and the lids to remain open. Continuous reflex blinking of either the upper or lower eyelids, or both, with or without complete lid closure, constituted a disinhibited, abnormal response.

3-5. Conjugate gaze (Critchley, 1956; Hurwitz, 1968; Adams and Hurwitz, 1974) The subject was asked to follow the examiner's finger as it was moved to all extremes of vertical and horizontal gaze. A ruler was placed such that deviation of the edge of the cornea in either plane could be measured. Upgaze was considered abnormal if the deviation from the midposition did not equal or exceed $5 \mathrm{~mm}$. Downgaze and lateral gaze were abnormal if deviation from the midposition was restricted to less than $7 \mathrm{~mm}$. ( $1 \mathrm{~mm}$ equals $7^{\circ}$ visual axis deviation, Hirschberg, 1885.)

6. Visual tracking (Rodin, 1964) The subject was instructed to hold his head still and follow the examiner's index finger as it was moved between both extremes of horizontal gaze. The eyes should have moved smoothly and without difficulty. Irregular, hesitant, or jerking saccades were considered abnormal.

7. Snout reflex (Schlezinger, 1938; Bieber, 1940; Ekbom et al., 1952; Ansink, 1962; Ingram, 1962;
Paulson and Gottlieb, 1968; Klawans et al., 1971; Villeneuve et al., 1974) Using the middle phalange of the flexed index finger, the examiner firmly pressed the subject's relaxed lips, then drew the finger away. Any contraction of the orbicularis oris to this stimulus resulted in a puckering of the lips. This was considered a normal response if elicited by a sharp blow of the reflex hammer to the examiner's finger placed on the subject's lips. However, the presence of the response to minimal pressure without use of the hammer was considered abnormal.

8. Suck reflex (Schlezinger, 1938; Bieber, 1940; Ekbom et al., 1952; Ingram, 1962; Paulson and Gottlieb, 1968) The examiner firmly placed the knuckle of the flexed index finger between the subject's lips. There should have been no response. Any pursing or sucking motion by the subject's lips was recorded as a disinhibited and abnormal response.

9-10. Visual and tactile rooting (Bieber, 1940; Ingram, 1962) In visual rooting, the examiner used an orally unfamiliar object-for example, pen, piece of paper-to approach the subject's mouth from within his visual fields. Absence of response was normal. Any anticipatory opening of the mouth, with or without turning toward the object, was considered disinhibited and abnormal. In testing tactile rooting, the examiner scratched each cheek of the subject with his index finger and observed for the same response.

11. Forced biting An orally unfamiliar object was placed in the mouth of the subject. Any tendency to bite down or hold onto the object was abnormal. Inability to release the object upon command by the examiner confirmed the response as abnormal.

12-13. Grasp reflex (Adie and Critchley, 1927; Bucy, 1931; Walshe, 1935; Bieber, 1940; Seyffarth and Denny-Brown, 1948; Paulson and Gottlieb, 1968; Shahani et al., 1970; Villeneuve et al., 1974) This reflex was tested both with and without distraction. First the subject was told, 'Do not hold on', while the examiner used his own finger to stroke the palmar surface of the subject's hand. Next, the subject was distracted by being instructed to spell a simple word such as 'fist' both forward and backward. Each hand was tested without distraction then with distraction. The addition of a second task ('spell fist backwards') to the first task ('do not hold on') increased the stress on the subject and allowed a disinhibited 
reflex to become manifest. Absence of response of the subject's hands was normal. Flexion of the fingers in an attempt to grasp, or firm closure around the examiner's finger by the subject was considered disinhibited and abnormal.

14. Palmomental reflex (Blake and Kunkle, 1951; August and Miller, 1952; McLaughlin and Haines, 1953; Bracha, 1958; Ansink, 1962; McDonald et al., 1963; Otomo, 1965; Hurwitz, 1968; Paulson and Gottlieb, 1968; Dalby, 1970; Adams and Hurwitz, 1974; Little and Masotti, 1974; Villeneuve et al., 1974) The subject was instructed to look at the examiner's nose and remain quiet. Using the nail of his thumb, the examiner firmly stroked the thenar eminence of the subject's hand 10 consecutive times. The stimulus was noxious in intensity and not administered to the palm or hypothenar eminence where the response was less likely to be produced. The examiner observed the ipsilateral mentalis muscle of the chin for any degree of contraction with each stroke. Four or fewer consecutive mentalis contractions were considered within normal limits. Five or more mentalis contractions were considered disinhibited and abnormal. Each side was tested.

15-17. Paratonia (Critchley, 1956; Paulson and Gottlieb, 1968; Wells, 1971; Adams and Hurwitz, 1974; Villeneuve et al., 1974) The examiner tested the subject's resting muscle tone in the arms and legs by passive extension and flexion. Normal tone should have been present. An irregular opposition to the examiner's movements after instructions to relax resulted in a 'catching' sensation. This was considered abnormal and could be differentiated from the full range, regular rigidity, or cog-wheeling of Parkinsonism and the clasp-knife phenomenon of spasticity. A further variation of the test for paratonia was limb placement. The examiner held the subject's arm up and told him to relax, letting the examiner do all the work. Then the examiner dropped his hands. The subject's arm should have fallen at the same time. Any delay in dropping of the arm was considered abnormal after Parkinsonian rigidity and spasticity had been excluded.

18-19. Perseveration (Critchley, 1956; Allison, 1966; Hurwitz, 1968; Adams and Hurwitz, 1974; Villeneuve et al., 1974) The examiner proceeded from irregular to regular cycles of passive extension and flexion of the subject's limb. After a few cycles, the subject's limb was released. Absence of movement was normal. Active continuation of the passive movement was considered abnormal perseveration of motor activity. Both arms and legs were tested.

20-24. Impersistence (Berlin, 1955; Joynt et al., 1962; Ben-Yishay et al., 1968) The inability to sustain motor activity was tested in five ways: (i) the subject was instructed to close his eyes and keep them closed. The subject should have been able to maintain this activity for more than 15 seconds. Any eye opening in 15 seconds or less was abnormal (impersistence on eye closure); (ii-iii) the subject was instructed to protrude his tongue with eyes open and while blindfolded. The tongue should have been held out for more than 20 seconds. Inability to keep the tongue out for 20 seconds in either situation was abnormal (impersistence on tongue protrusion, eyes either open or blindfolded); (iv) the subject was instructed to fix his gaze on the examiner's finger at approximately the 45 degree angle in the horizontal plane of the right and left visual fields for 30 seconds. One deviation from the examiner's finger in each field or more than one deviation in one field was abnormal (impersistence on lateral gaze); (v) the subject was also instructed to protrude his tongue and close his eyes. Inability to sustain this activity for 10 seconds was considered abnormal (impersistence on eye closure/tongue protrusion).

25-26. Face-hand stimulation (Fink et al., 1952; Bender et al., 1954; Kahn et al., 1960) The subject was instructed to close his eyes and describe where he had been touched by the examiner. The examiner alternately touched the right cheek, then left hand and right cheek together and simultaneously, right hand and left cheek together and simultaneously, and so on, recording the subject's response to each stimulation. Accurate localisation of all stimuli after three mistakes was considered normal. Improper localisation or extinguishing of one of the places stimulated was considered abnormal (double simultaneous stimulation (DSS), either incorrectly localised or extinguished).

27. Plantar response (Babinski, 1898; Brain and Curran, 1932; Goldstein, 1938; Wartenberg, 1945; Walshe, 1956; Brain and Wilkinson, 1959; Manfredi et al., 1975) The lateral aspect of each foot was stimulated with a noxious instrument (pointed end of the reflex hammer) and the movement of the toes was observed. This technique was employed to avoid confusion with the tonic foot grasp evoked by stimulation placed more medially on the plantar surface. Plantar flexion of the great toe or no movement was considered normal. 
Dorsiflexion of the great toe denoted the Babinski sign. Any uncertain response was described as equivocal.

28-29. Vibration (Klawans et al., 1971) The sensory capacity of the arms and legs was assessed using a C128 tuning fork. Any reported decrease in sensation was considered abnormal.

\section{0-31. Post-hyperventilation apnoea (PHVA)} (Plum et al., 1962; Jennett et al., 1974) The subject was instructed to take five breaths as rapidly and as deeply as possible. The time between the fifth and sixth breaths was determined without informing the subject. If this interval exceeded 10 seconds, it was considered abnormal. Perseveration of inspirations beyond six breaths (number of breaths) forced the examiner to command the subject to stop, and responses of this kind were not recorded.

32. Oculocephalic reflex (Szentagothai, 1950; Plum and Posner, 1972) The subject in the supine or sitting position was instructed to keep his eyes open and not to fixate on anything in particular. The examiner rotated the head and observed the eyes. Deviation of the eyes in the direction of the head movement was normal. If the eyes held the original position the reflex was disinhibited and abnormal.

33-45. Mental status examination (Kahn et al., 1960; Bender, 1966; Smith, 1967) Thirteen questions were given in the following order so that memory could be tested with distraction after three to five minutes.

i-ii. The examiner gave three items ('red, table, 23 Broadway') and asked the subject to repeat them. If there was difficulty with immediate repetition, the process was repeated to a maximum of three times. Then the subject was stressed to remember the items for later in the exam. The subject should have been able to repeat the items without error both at the onset (immediate memory) and termination (recall memory) of the mental status exam. It is important not to suggest how many items were given originally.

iii. Where are you? No error allowed.

iv. What kind of place is this? No error allowed.

$v$. What is the date? It was considered normal if the date was within three days of the actual date. vi. What day of the week is this? No error allowed.

vii. What time is it? It was considered normal if the time was within one hour of the actual time. viii. Who is the present President of the United States? No error allowed.

ix. Name the past Presidents of the United States in reverse order from the present one. The knowledge of past presidents is a function of age: a 20 year old should have known Ford, Nixon, Johnson, and a 40 year old should have known these plus Kennedy and Eisenhower, while a 60 year old should have known these plus Truman and Roosevelt.

$x$. In your opinion, what is the largest city in the country? Any large city was acceptable while states, local towns, and foreign cities were not.

xi. Subtract seven from 100 and continue subtracting seven from your answer (serial sevens). Serial sevens were abnormal if the subject made more than one error in subtraction. Abnormalities in the pattern of responses to serial sevens were not analysed because of lack of agreement on their meaning.

xii. Spell 'world' forward and backward (reversal, 'world'). Errors in forward spelling were ignored if the reverse sequence of the misspelled word was correct.

xiii. Give the days of the week forward and backward (reversal, days of week). No errors allowed.

\section{Results}

Table 2 delineates some relevant characteristics of the subjects in the four cognitive categories. It also shows the number of abnormal responses found in each category during the examination of physical signs and mental status questions.

The number of abnormal responses increased directly with increasing degrees of cognitive im-

Table 2 Characteristics of patients in four cognitive categories

\begin{tabular}{|c|c|c|c|c|c|}
\hline & \multicolumn{5}{|c|}{ Cognitive function of original subjects* } \\
\hline & \multirow[b]{2}{*}{ Normal } & \multicolumn{3}{|l|}{ Impaired } & \multirow{2}{*}{$\begin{array}{l}\text { All } \\
\text { Categories }\end{array}$} \\
\hline & & Mildly & Moderately & Markedly & \\
\hline $\begin{array}{l}\text { Number } \\
\text { Mean age } \\
\text { (range) }\end{array}$ & $\begin{array}{l}18 \\
29.2 \\
(17-65)\end{array}$ & $\begin{array}{l}25 \\
38.7 \\
(16-66)\end{array}$ & $\begin{array}{l}23 \\
52.8 \\
(20-75)\end{array}$ & $\begin{array}{l}10 \\
66.4 \\
(46-80)\end{array}$ & $\begin{array}{l}76 \\
43.8 \\
(16-80)\end{array}$ \\
\hline $\begin{array}{l}\text { Average } \\
\text { number of } \\
\text { abnormal } \\
\text { responses } \\
\text { per subject }\end{array}$ & 2.9 & 6.0 & 13.9 & 19.1 & 9.4 \\
\hline $\begin{array}{l}\text { Abnormal } \\
\text { responses } \\
\text { per category } \\
(\%)\end{array}$ & 6.6 & 13.5 & 31.3 & 42.7 & 21.1 \\
\hline
\end{tabular}

*Determined by neuropsychological evaluation (see Methods). 
pairment. A simple one-way analysis of variance reveals this to be a highly significant relationship $(\mathrm{F}=49.93$, df $=3,71 \mathrm{P}<0.001)$.

Table 2, however, also reveals that the four groups differ in age. Could our data reflect an increased incidence of abnormal responses in older patients rather than a particular association between abnormal responses and cognitive impairment? The data were examined in two different ways to attempt to answer this question.

First, an analysis of covariance was performed in which the number of abnormal responses in the four groups was the criterion variable and age was the covariate. This analysis (Winer, 1962) served to eliminate statistically the correlation between age and number of abnormal responses (Pearson $r=+.61, \mathrm{P}<0.01$ ), and then re-examined group differences with the effect of age removed. The analysis of covariance showed that the group differences were still highly significant with the effect of age removed $(\mathrm{F}=24.47, \mathrm{df}=3,71$ $\mathbf{P}<0.001$ ).

A second related analysis was performed in which only the data for subjects between the ages of 40 and 65 years were considered. The number of such subjects in cognitive categories 1-4 were, respectively, five, 12, 11, and five. A one-way analysis of variance showed no significant difference in age among these four groups. The average number of abnormal responses in the four groups were respectively $3.6,6.4,16.0$, and 19.8 . A oneway analysis of variance showed these group differences to be significant $(F=4.57, \mathrm{df}=3,28$, $\mathbf{p}<0.01)$. Thus, there is good evidence that the total number of abnormal responses is directly related to the degree of cognitive impairment independent of age.

Table 3 summarises for each factor the rate of abnormal responses in subjects with normal cortical function (group 1): the false positive rate; and the rate of normal responses in cortically impaired individuals (groups 2, 3, and 4): the false negative rate. All 45 factors could not be tested in every subject for a variety of technical reasons.

The statistical significance of the relationship of each factor to normal or impaired cortical function was evaluated by a $\chi^{2}$ test. This was performed on a two by four table which contained the frequency of the presence or absence of the abnormal response for each cognitive category. The factors are listed in Table 3 in order of decreasing significance of their $\chi^{2}$ values. When the chi squared value is greater than or equal to 16.3 , the significance is $P<0.001$. When it is greater than or equal to 11.3 , the significance is $\mathbf{P}<0.01$.
Table 3 Summary of rate of abnormal responses in subjects with normal cortical function

\begin{tabular}{|c|c|c|c|c|c|}
\hline \multicolumn{2}{|c|}{ Response tested } & \multirow{2}{*}{$\begin{array}{l}x^{2} \\
32.01\end{array}$} & \multirow{2}{*}{$\begin{array}{l}\begin{array}{l}\text { Number } \\
\text { tested }\end{array} \\
75\end{array}$} & \multirow{2}{*}{$\begin{array}{l}\begin{array}{l}\text { False } \\
\text { positive } \\
(\%)\end{array} \\
5.6\end{array}$} & \multirow{2}{*}{$\begin{array}{l}\begin{array}{l}\text { False } \\
\text { negative } \\
(\%)\end{array} \\
47.4\end{array}$} \\
\hline \multirow[t]{13}{*}{$P<0.001$} & Paratonia (arms) & & & & \\
\hline & Upgaze & 30.29 & 76 & 11.1 & \\
\hline & Paratonia (legs) & 27.40 & 75 & 0 & 56.1 \\
\hline & Oculocephalic & 26.37 & 68 & $\mathbf{0}$ & 63.5 \\
\hline & $\begin{array}{l}\text { Nuchocephalic } \\
\text { PHVA (number }\end{array}$ & 25.29 & 75 & 5.6 & 48.3 \\
\hline & of breaths) & 24.56 & 73 & 5.6 & 83.6 \\
\hline & Serial sevens & 24.52 & 75 & 22.2 & 70.2 \\
\hline & $\begin{array}{l}\text { Visual tracking } \\
\text { Reversal (days }\end{array}$ & 24.11 & 76 & 16.1 & 46.6 \\
\hline & of week) & 23.18 & 73 & 0 & 91.1 \\
\hline & Limb placement & 21.41 & 75 & 5.6 & 52.6 \\
\hline & Lateral gaze & 20.86 & 76 & 5.6 & 62.1 \\
\hline & presidents & 16.47 & 75 & 22.2 & 42.1 \\
\hline & Suck & 16.30 & 76 & 0 & 56.9 \\
\hline \multirow[t]{10}{*}{$P<0.01$} & DSS (extinguish) & 16.14 & 76 & 0 & 81.0 \\
\hline & $\begin{array}{l}\text { Grasp (without } \\
\text { distraction) }\end{array}$ & 16.10 & 76 & $\mathbf{0}$ & 87.9 \\
\hline & Kind of place & 15.07 & 74 & 0 & 96.5 \\
\hline & Snout & 14.23 & 76 & 11.1 & 60.4 \\
\hline & Grasp (with & 14.11 & 76 & 0 & 79.3 \\
\hline & Downgaze & 13.18 & 76 & 11.1 & 56.9 \\
\hline & PHVA (time to & 1253 & 69 & 5.6 & 84.3 \\
\hline & $\begin{array}{l}\text { sixth breath) } \\
\text { Glabellar blink }\end{array}$ & $\begin{array}{l}12.33 \\
12.49\end{array}$ & 75 & 29.4 & $\begin{array}{l}84.3 \\
27.6\end{array}$ \\
\hline & Impersistence on & & & & \\
\hline & lateral gaze & 11.74 & 68 & 29.4 & 39.2 \\
\hline \multirow{6}{*}{$P<0.05$} & Reversal ('world') & 10.50 & 74 & 23.5 & 50.9 \\
\hline & Time & 10.13 & 74 & 0 & 83.9 \\
\hline & Memory (recall) & 9.11 & 75 & & \\
\hline & $\begin{array}{l}\text { Impersistence on } \\
\text { eye/tongue }\end{array}$ & & & & \\
\hline & protrusion & 8.47 & 75 & 5.6 & 87.7 \\
\hline & Palmomental & 8.02 & 75 & 5.6 & 70.2 \\
\hline \multirow[t]{24}{*}{$\begin{array}{l}\text { Not sig- } \\
\text { nificant }\end{array}$} & $\begin{array}{l}\text { Motor persever- } \\
\text { ation (arms) }\end{array}$ & 7.43 & 75 & $\mathbf{0}$ & 98.3 \\
\hline & Vibration & & & & \\
\hline & sense (legs) & 6.72 & 73 & 5.6 & 89.1 \\
\hline & Date & 6.68 & 75 & 5.6 & 84.2 \\
\hline & Largest city & 6.23 & 74 & 0 & 93.0 \\
\hline & Babinski & 5.86 & 71 & 5.9 & 85.2 \\
\hline & $\begin{array}{l}\text { Impersistence on } \\
\text { tongue protru- }\end{array}$ & & & & \\
\hline & $\begin{array}{l}\text { tongue protru- } \\
\text { sion (eyes open) }\end{array}$ & 5.60 & 75 & 5.6 & 84.2 \\
\hline & Where & 5.47 & 75 & 5.6 & 93.0 \\
\hline & $\begin{array}{l}\text { Impersistence on } \\
\text { eye closure }\end{array}$ & 4.65 & 75 & 0 & 96.5 \\
\hline & $\begin{array}{l}\text { eye closure } \\
\text { Recall of present }\end{array}$ & $\begin{array}{l}4.63 \\
4.32\end{array}$ & $\begin{array}{l}75 \\
75\end{array}$ & 0 & 93.0 \\
\hline & president & & & & \\
\hline & $\begin{array}{l}\text { Motor persever- } \\
\text { ation (legs) }\end{array}$ & 3.90 & 75 & $\mathbf{0}$ & 96.5 \\
\hline & Day & 3.56 & 75 & 11.1 & 84.2 \\
\hline & DSS (incorrectly & & & & \\
\hline & localised & 3.36 & 75 & $\mathbf{0}$ & 91.2 \\
\hline & $\begin{array}{l}\text { Impersistence on } \\
\text { tongue protru- }\end{array}$ & & & & \\
\hline & $\begin{array}{l}\text { sion (eyes } \\
\text { blindfolded) }\end{array}$ & 3.32 & 72 & 5.9 & 89.1 \\
\hline & Forced bite & 2.34 & 76 & 0 & 98.3 \\
\hline & $\begin{array}{l}\text { Memory } \\
\text { (immediate) }\end{array}$ & 1.70 & 76 & 0 & 100 \\
\hline & Vibration sense & & & & \\
\hline & (arms) & 1.70 & 73 & 0 & 100 \\
\hline & Root (visual) & 1.70 & 75 & $\begin{array}{l}0 \\
0\end{array}$ & $\begin{array}{l}100 \\
100\end{array}$ \\
\hline & Root (tactile) & 1.70 & 75 & $\mathbf{0}$ & \\
\hline
\end{tabular}


When it is greater than or equal to 7.8 , the significance is $\mathbf{P}<0.05$. A chi squared value of less than 7.8 indicates that the results obtained for that factor are not significantly different from chance. Twenty-seven of the factors were significantly related to the level of cognitive impairment while 18 were not.

The significant factors $(\mathrm{P}<0.05)$ with the lowest false negative rates were selected in order to assemble an effective battery of tests to screen for diffuse cortical dysfunction. Factors with false negative rates greater than $60 \%$ were arbitrarily considered to be poor predictors. The false positive rates for all 27 significant factors were considered acceptable. The 13 factors listed in Table 4 represent those with false negative rates less than $60 \%$.

As a matter of interest, the original data were re-examined using only these 13 factors. Table 5 shows the average number of abnormal responses per subject in this screening battery for each cognitive category (groups 1-4). The number of abnormal responses per person increases with increasing degrees of cerebral dysfunction, and more than two abnormal responses was usually associated with impaired cognitive function. The 76 subjects were classified as normal (two or less abnormal factors on the screening battery) or

Table 4 List of factors selected for an effective battery of screening tests for diffuse cortical dysfunction

\begin{tabular}{l}
\hline Factors with false negative rates less than $60 \%$ \\
\hline Nuchocephalic reflex \\
Glabellar blink \\
Suck \\
Upgaze \\
Downgaze \\
Visual tracking \\
Lateral gaze impersistence \\
Paratonia of both arms \\
Paratonia of both legs \\
Limb placement \\
Accurate spelling of 'world' in reverse \\
Accurate order of past presidents in reverse \\
Accurate recall of three items over time with distraction
\end{tabular}

Table 5 Average number of abnormal responses per subject in selected screening battery by cognitive category

\begin{tabular}{lcccc}
\hline $\begin{array}{l}\text { Screening battery } \\
\text { responses } \\
\text { (maximum }=13)\end{array}$ & \multicolumn{5}{c}{ Cognitive function of original subjects* } \\
\cline { 2 - 5 } & Normal & \multicolumn{3}{c}{ Impaired } \\
\cline { 2 - 5 } & Mildly & Moderately & Markedly \\
\hline $\begin{array}{l}\text { Number of abnormal } \\
\text { responses per person } \\
\text { (range) }\end{array}$ & $\begin{array}{c}1.78 \\
(0-6)\end{array}$ & $\begin{array}{c}4.32 \\
(1-8)\end{array}$ & $\begin{array}{c}7.00 \\
(1-12)\end{array}$ & $\begin{array}{c}8.70 \\
(4-13)\end{array}$ \\
\hline
\end{tabular}

*Determined by neuropsychological evaluation (see Methods). impaired (three or more abnormal factors). The results are shown in Table 6 . The screening

Table 6 Results of classification of patients by selected screening battery

\begin{tabular}{lllll}
\hline \multirow{2}{*}{$\begin{array}{l}\text { Prediction of } \\
\text { cognitive function }\end{array}$} & \multicolumn{3}{l}{ Cognitive function of original subjects } \\
\cline { 2 - 5 } & \multicolumn{4}{c}{ Impaired } \\
\cline { 2 - 5 } \cline { 3 - 5 } & Normal & Mildly & Moderately & Markedly \\
\hline Normal & 16 & 8 & 1 & 0 \\
Impaired $\dagger$ & 2 & 17 & 22 & 10 \\
Total & 18 & 25 & 23 & 10 \\
\% correct & 89 & 64 & 96 & 100 \\
& & &
\end{tabular}

* Determined by neuropsychological evaluation (see Methods).

†Three or more abnormal responses.

battery correctly predicted normal cognitive function in $89 \%$ of those subjects with normal cortical function. Therefore, the rate of prediction of abnormal cortical function in normal subjects (the false positive rate) was $11 \%$. With increasing degrees of impairment, the screening battery correctly predicted cortical dysfunction in $64 \%$ of mildly impaired subjects, in $96 \%$ of moderately impaired subjects, and in $100 \%$ of markedly impaired subjects. The rate of prediction of normal cognitive function among all cortically impaired subjects (the false negative rate) was $16 \%$.

The above analysis suffers from being circular in that the 13 factors were derived from the same data on which the subsequent analysis was based. For this reason a small cross-validation study was performed. Twenty-three new subjects were selected randomly from those referred to the Neuropsychology Laboratory, and the short battery of 13 factors was given to them. Again, no patient was selected with neurological or neuropsychological evidence of focal cortical dysfunction. Each patient was independently assigned to one of the four cognitive categories on the basis of his or her neuropsychological test results alone. The resultant data are shown in Table 7. Table 8 shows the relationship between cognitive function and the presence of two or less abnormal factors (predicted to be normal) or three or more abnormal factors (predicted to be impaired). The association is just as strong in the cross-validation as in the original data.

\section{Discussion}

This study assessed the usefulness of a number of physical signs and mental status questions associated with the clinical recognition of diffuse cortical dysfunction. Each factor was examined 
Table 7 Classification of new subjects by results of neuropsychological tests alone

\begin{tabular}{|c|c|c|c|c|c|}
\hline & \multicolumn{5}{|c|}{ Cognitive function of new subjects* } \\
\hline & \multirow[b]{2}{*}{ Normal } & \multicolumn{4}{|c|}{ Impaired } \\
\hline & & Mildly & Moderately & Markedly & Total \\
\hline Number & 5 & 10 & 7 & 1 & 23 \\
\hline $\begin{array}{l}\text { Number of } \\
\text { abnormal responses } \\
\text { on screening } \\
\text { battery for each } \\
\text { s:sbject }\end{array}$ & $\begin{array}{l}3 \\
2 \\
1 \\
1 \\
0\end{array}$ & $\begin{array}{l}6 \\
6 \\
6 \\
4 \\
4 \\
4 \\
3 \\
3 \\
2 \\
2\end{array}$ & $\begin{array}{r}10 \\
9 \\
7 \\
7 \\
6 \\
5 \\
5\end{array}$ & 8 & \\
\hline $\begin{array}{l}\text { Average number } \\
\text { of abnormal } \\
\text { responses per } \\
\text { subject }\end{array}$ & 1.4 & 4.0 & 7.0 & 8.0 & 4.4 \\
\hline
\end{tabular}

*Determined by neuropsychological evaluation (see Methods).

Table 8 Relationship between cognitive function and the presence of abnormal factors

\begin{tabular}{lcccc}
\hline $\begin{array}{l}\text { Prediction of } \\
\text { cognitive function } \\
\text { by screening battery }\end{array}$ & \multicolumn{3}{l}{\begin{tabular}{l} 
Cognitive function of new subjects* \\
\cline { 2 - 5 }
\end{tabular}} & \multicolumn{4}{c}{ Impaired } \\
\cline { 2 - 5 } \cline { 2 - 4 } & Normal & Mildly & Moderately & Markedly \\
\hline Normal & 4 & 2 & 0 & 0 \\
Impaired $\dagger$ & 1 & 8 & 7 & 1 \\
Total & 5 & 10 & 7 & 1 \\
\% correct & 80 & 80 & 100 & 100 \\
\hline
\end{tabular}

*Ditermined by neuropsychological evaluation (see Methods).

+Three or more abnormal responses.

individually for its ability to predict impairment as measured by the Halstead-Reitan Neuropsychological Battery. It is significant that the subjects evaluated were those who represent the population at risk for mild diffuse cortical impairment - that is, those referred for neuropsychological evaluation-and not the population with severe and obvious diffuse cortical dysfunction.

The results show that 18 factors had no significant statistical association with the presence or absence of diffuse dysfunction. These included such commonly used mental status questions as the date, day of the week, geographic location, present president, and immediate memory (the ability to repeat three items immediately without distraction). Also, the 'regressive' signs of motor perseveration, visual and tactile rooting, and forced biting were not significant predictors. Other factors were significantly associated with cognitive impairment but were of little predictive value because of prohibitively high false negative rates. These included such physical signs as the grasp (both with and without distraction), palmomental, snout, and oculocephalic reflexes as well as motor impersistence and post-hyperventilation apnoea. Also, frequently used mental status questions such as serial sevens, kind of place, time of day, and saying the days of the week in reverse order were associated with very high false negative rates.

The remaining 13 significantly associated factors were combined to assess their predictive value as a short test battery. They were initially applied to the original data (from which they came) and found to be highly accurate in their prediction of normal or impaired cognitive function. Subsequently, a cross-validation study was performed with a new sample of patients and it confirmed the predictive utility of the 13 item battery.

The screening battery possesses several interesting characteristics. All 13 factors have clearly identifiable present or absent responses. Ten of the 13 factors require no verbal response from the subject. The relationship of the nuchocephalic reflex to diffuse cerebral dysfunction has been described previously. It was shown that, whether inhibited or disinhibited, the nuchocephalic reflex predicted correctly the state of higher cortical function in $75-80 \%$ of all subjects older than 16 years of age (Jenkyn et al., 1975). It is interesting that the presence of a glabellar blink, previously associated with Parkinson's disease, is also related to the presence of diffuse cerebral dysfunction. This suggests that diffuse cortical impairment may be an integral part of the degenerative process of Parkinsonism, or that diffuse disease involves the basal ganglia or their connections (Pearce, 1974a, b; Drachman and Stahl, 1975). Among the infantile feeding reflexes to reappear with diffuse cortical dysfunction, the suck reflex is notable for its predictive value. The snout reflex, which appears to differ from the suck reflex only in the strength of the eliciting stimulus, was excluded from the battery because its false negative rate $(60.4 \%)$ was just greater than the arbitrary $60 \%$ rate that was set as the acceptable upper limit.

Of great interest is the usefulness of observing extraocular movements in this battery. Innervation of normal voluntary vertical gaze (both upward and downward) is associated with both hemispheres, is not localised to any particular cortical areas, and might be impaired with diffuse dysfunction (Critchley, 1956; Hurwitz, 1968; Hoyt and Daroff, 1971; Adams and Hurwitz, 1974). Contralateral horizontal gaze, a function that may 
be elicited from cortical stimulation of most areas of the hemisphere, but especially area 8 of Brodman (Carpenter, 1971), had a false negative rate of $62.1 \%$ and, like the snout reflex, just missed the cutoff for inclusion in the screening battery. Impersistence on lateral gaze may be secondary to organic dysfunction of the horizontal gaze centres of the cerebral cortex, or more likely results from the psychological need to maximise sensory input in an individual who is finding it increasingly more difficult to maintain control over and contact with the environment. Visual tracking, thought to be a function of the occipital lobes, may be impaired bilaterally in a diffuse process, or may require bilateral hemispheric innervation for smooth pursuit (Rodin, 1964).

Paratonia (gegenhalten) of arms and legs, and perseveration of limb placement (a phenomenon also described as catatonia) may be the result of loss of the capacity to inhibit resting muscle tone. Poor recall of past presidents and three items over time with distraction, and inaccurate reverse spelling of 'world' confirm that both remote and recent memory and learning capabilities are disrupted in diffuse cerebral dysfunction.

One significant attribute of the screening battery is the ease with which it may be incorporated into the physical examination without increasing the expenditure of time. The nuchocephalic reflex may be evaluated while the Romberg test is performed. The glabellar blink and suck are tested while examining the head and mouth. Conjugate vertical gaze and visual tracking require only observation during the routine examination of extraocular movements. Impersistence on lateral gaze is observed while checking for nystagmus. Paratonia may be elicited while evaluating muscle tone and the limb placement manoeuvre is easily added at this point. The mental status examination is sufficiently adaptable to include the recall of past presidents, reverse spelling of 'world' (having proof that the subject can spell it accurately forward), and the recall of three items over time (three to five minutes) with distraction. It is only necessary to tally the number of abnormal responses in order to have a rapid indication of the state of higher cortical function at the bedside.

\section{References}

Adams, G. F., and Hurwitz, L. J. (1974). Cerebrovascular Disability and the Aging Brain. pp. 28-50. Churchill Livingstone: Edinburgh and London.

Adie, W. J., and Critchley, M. (1927). Forced grasping and groping. Brain, 50, 142-170.

Allison, R. S. (1966), Perseveration as a sign of diffuse and focal brain damage. British Medical Journal, 2, $1027-1032$.

Ansink, J. J. (1962). Physiologic and clinical investigations into four brainstem reflexes. Neurology (Minneapolis), 12, 320-328.

August, B., and Miller, R. B. (1952). Clinical value of the palmomental reflex. Journal of the American Medical Association, 148, 120-121.

Babinski, M. (1898). Du phénomène des orteils et de sa valeur semiologique. La Semaine Médicale, 18, 321-322.

Ben-Yishay, Y., Diller, L., Gerstman, L., and Haas, A. (1968). The relationship between impersistence, intellectual function and outcome of rehabilitation in patients with left hemiplegia. Neurology (Minneapolis), 18, 852-861.

Bender, M. B. (1966). Diagnostic aids in the mental and aphasic status. Journal of the Mount Sinai Hospital, 33, 208-212.

Bender, M. B., Green, M. A., and Fink, M. (1954). Patterns of perceptual organization with simultaneous stimuli. Archives of Neurology and Psychiatry (Chicago), 72, 233-255.

Berlin, L. (1955). Compulsive eye opening and associated phenomena. Archives of Neurology and Psychiatry (Chicago), 73, 597-601.

Bieber, I. (1940). Grasping and sucking. Journal of Nervous and Mental Disease, 91, 31-36.

Blake, J. R., and Kunkle, E. C. (1951). The palmomental reflex: A physiological and clinical analysis. Archives of Neurology and Psychiatry (Chicago), 65, 337-345.

Bracha, S. (1958). The clinical value of the pollicomental reflex in neuropathology. Journal of Nervous and Mental Disease, 127, 91-94.

Brain, W. R., and Curran, R. D. (1932). The graspreflex of the foot. Brain, 55, 347-356.

Brain, W. R., and Wilkinson, M. (1959). Observations on the extensor plantar reflex and its relationship to the functions of the pyramidal tract. Brain, 82, 297-320.

Bucy, P. (1931). Reflex-grasping associated with tumours not involving the frontal lobes. Brain, 54, 480-491.

Carpenter, M. B. (1971). Central oculomotor pathways. In The Control of Eye Movements. Edited by P. Bach-y-rita, C. C. Collins, and J. E. Hyde. Academic Press: New York.

Critchley, M. (1956). Neurologic changes in the aged. Journal of Chronic Diseases, 3, 459-477.

Dalby, M. A. (1970). The diagnostic value of the palmo-mental reflex. Acta Neurologica Scandinavica, 46, 601-608.

Drachman, D. A., and Stahl, S. (1975). Extrapyramidal dementia and levodopa. Lancet, 1, 809.

Ekbom, K. A.. Jernelius, B., and Kugelberg, E. (1952). Perioral reflexes. Neurology (Minneapolis), 2, 103111.

Fink, M., Green, M., and Bender, M. B. (1952). The face-hand test as a diagnostic sign of organic mental syndrome. Neurology (Minneapolis), 2, 46-58.

Goldstein, K. (1938). The tonic foot response to stimu- 
lation of the sole: Its physiological significance and diagnostic value. Brain, 61, 269-283.

Hirschberg, J. (1885). Uber die messung des schieldgrades und die dosierung der schiel-operation. Zentralblatt für Praktische Augenheilkunde, 8, 325.

Hoyt, W. F., and Daroff, R. B. (1971). Supranuclear disorders of ocular control systems in man: Clinical, anatomical and physiological correlations. In The Control of Eye Movements. Edited by P. Bach-yrita, C. C. Collins, and J. E. Hyde. Academic Press: New York.

Humphrey, T. (1964). Some correlations between the appearance of human fetal reflexes and the development of the nervous system. Progress in Brain Research, 4, 93-135.

Hurwitz, L. J. (1968). Neurological aspects of old age and capacity. Gerontology Clinics, 10, 146-156.

Ingram, T. T. S. (1962). Clinical significance of the infantile feeding reflexes. Developmental Medicine and Child Neurology, 4, 159-169.

Isaacs, B., and Akhtar, A. J. (1972). The set test: A rapid test of mental function in old people. Age and Aging, 1, 222-226.

Jenkyn, L. R., Walsh, D. B., Walsh, B. T., Culver, C. M., and Reeves, A. G. (1975). The nuchocephalic reflex. Journal of Neurology, Neurosurgery, and Psychiatry, 38, 561-566.

Jennett. S., Ashbridge, K., and North, J. B. (1974). Post-hyperventilation apnoea in patients with brain damage. Journal of Neurology, Neurosurgery, and Psychiatry, 37, 388-396.

Joynt, R. J., Benton, A. L., and Fugel, M. L. (1962). Behavioral and pathological correlates of motor impersistence. Neurology (Minneapolis), 12, 876881.

Kahn, R. L., Goldfarb, A. I., Pollack, M., and Peck, A. (1960). Brief objective measures for the determination of mental status in the aged. American Journal of Psychiatry, 117, 326-328.

Katzman, R. (1976). The prevalence and malignancy of Alzheimer clisease. Archives of Neurology (Chicago), 33, 217-218.

Klawans, H. L., and Goodwin, J. A. (1969). Reversal of the glabellar reflex in Parkinsonism by L-dopa. Journal of Neurology, Neurosurgery, and Psychiatry, 32, 423-427.

Klawans, H. L., Tufo, H. M.. Ostfeld, A. M., Shekelle, R. B., and Kilbridge J. A. (1971). Neurologic examination in an elderly population. Diseases of the Nervous System, 32, 274-279.

Little, T. M., and Masotti, R. E. (1974). The palmomental reflex in normal and mentally retarded subjects. Developmental Medicine and Child Neurology, 16, 59-63.

McDonald, J. K., Kelley, J. J., Brock, L. D., and Bartunek, E. J. (1963). Variability of the palmomental reflex. Journal of Nervous and Mental Disease. 136, 207-215.

McLaughlin, J. J., and Haines, W. H. (1953). A clinical report on the palm-chin reflex. Disease of the Nervous System, 14, 378-380.
Manfredi, M., Sacco, G., and Sideri, G. (1975). The tonic ambulatory foot response: A clinical and electromyographic study. Brain, 98, 167-180.

Marsden, C. D., and Harrison, M. J. G. (1972). Outcome of investigation of patients with presenile dementia. British Medical Journal, 2, 249-252.

Otomo, E. (1965). The palmomental reflex in the aged. Geriatrics, 20, 901-905.

Paulson, G., and Gottlieb, G. (1968). Development reflexes: The reappearance of foetal and neonatal reflexes in aged patients. Brain, 91, 37-52.

Pearce, J. (1974a). Mental changes in Parkinsonism. British Medical Journal, 2, 445.

Pearce, J. (1974b). The extrapyramidal disorcler of Alzeheimer's disease. European Neurology, 12, 94 103.

Plum, F., Brown, H. W., and Snoep, E. (1962). Neurologic significance of post-hyperventilation apnea. Journal of the American Medical Association, 181, 1050-1055.

Plum, F., and Posner, J. B. (1972). The Diagnosis of Stupor and Coma. pp. 44-46. F. A. Davis Company: Philadelphia.

Reitan, R. M., and Davison, L. A. (1974). Clinical Neuropsychology: Current Status and Applications. pp. 365-384. Wiley and Sons: New York.

Rodin, E. A. (1964). Impaired ocular pursuit movements. Archives of Neurology (Chicago), 10, 327331.

Russell, E. W., Neuringer, C., and Goldstein, G. (1970). Assessment of Brain Damage: A Neuropsychological Key Approach. pp. 108-109. Wiley and Sons: New York.

Schlezinger, N. S. (1938). A study of the oral (orbicularis oris) reflex. Psychiatry Quarterly, 12, 629649.

Seyffarth, H., and Denny-Brown, D. (1948). The grasp reflex and the instinctive grasp reaction. Brain, 71, 109-183.

Shahani, B., Burrows, P., and Whitty, C. W. M. (1970). The grasp reflex and perseveration. Brain, 93, 181-192.

Smith, A. (1967). The serial sevens subtraction test. Archives of Neurology (Chicago), 17, 78-80.

Szentagothai, J. (1950). The elementary vestibuloocular reflex arc. Journal of Neurophysiology, 13, 395-407.

Villeneuve, A., Turcotte, J., Bouchard, M., Cote, J. M., and Jus, A. (1974). Release phenomena and iterative activities in psychiatric geriatric patients. Canadian Medical Association Journal, 110, 147153.

Walshe, F. M. R. (1935). On the 'syndrome of the premotor cortex' (Fulton) and the definition of the terms 'premotor' and 'motor': with a consideration of Jackson's views on the cortical representation of movements. Brain, 58, 49-80.

Walshe, F. M. R. (1956). The Babinski plantar response, its forms and its physiological and pathological significance. Brain, 79, 529-556. 
Wartenberg, R. (1945). The Examination of Reflexes: A Simplification. pp. 142-177. Year Book Publishers: Chicago.
Wells, C. E. (1971). Dementia, pp. 210-232. F. A. Davis Company: Philadelphia.

Winer, B. J. (1962). Statistical Principles in Experimental Design. McGraw-Hill: New York. 